\title{
Evasão no Ensino Superior Privado
}

\author{
Dropout in Private Higher Education \\ Evasión de la Educación Superior Privada
}

\author{
Walter Chalegre Santos \\ ORCID: https://orcid.org/0000-0001-8906-5502 \\ Faculdade Metodista Centenário, Brasil \\ E-mail:wcsanto@yahoo.com.br
}

\begin{abstract}
Resumo
A evasão ou abandono no âmbito da educação superior é uma temática que vem sendo estudada de forma mais significativa nos últimos anos. Insere-se não só na preocupação das políticas afirmativas de inclusão do estudante, mas, em especial, das instituições privadas, tendo em vista serem as que possuem os maiores percentuais de estudantes nessa situação e, por conseguinte, as principais interessadas em mantê-los em seus cursos. Este artigo, então, tem como objetivo geral analisar os motivos que levam os alunos a evadirem do Ensino Superior presencial Privado. A metodologia utilizada para esta pesquisa é composta por procedimentos de análise bibliográfica e documental. Para isso, são utilizados acervo digital, com auxílio de internet para realizações revisões bibliográficas, artigos, monografias e dissertações sobre tal temática. $\mathrm{O}$ estudo indica que o pouco conhecimento sobre o curso escolhido, as incertezas em relação às possibilidades de carreira na área, as dificuldades financeiras dos estudantes, o baixo desempenho acadêmico e a necessidade de articular tempo para estudo e trabalho estão entre os motivos mais citados para o abandono no Ensino Superior. Portanto, para se trabalhar um projeto de redução da evasão, as Instituições de Ensino Superior deverão fazer um diagnóstico específico de sua realidade, analisando profundamente as variáveis internas e externas da instituição e de seus alunos.
\end{abstract}

Palavras-chave: Ensino Superior; Evasão; Rendimento; Fatores Determinantes.

\begin{abstract}
Dropout in higher education is a topic that has been studied more significantly in recent years. It fits not only in the concern of affirmative policies for student inclusion, but, in particular, of private institutions, considering that they have the highest percentage of students in this situation and, therefore, the main interested in keeping them in their courses. This article, then, has as a general objective to analyze the reasons that lead students to drop out of on-site Higher Education. The methodology used for this research is based on bibliographic and documentary analysis procedures. For this, a digital collection is used, with the aid of the internet, for bibliographical reviews, articles, monographs and dissertations on this subject. The study indicates that the lack of knowledge about the chosen course, uncertainties regarding career possibilities in the area, students' financial difficulties, poor academic performance and the need to articulate time between study and work are among the most cited reasons for dropout in Higher Education. Therefore, in order to work on a dropout reduction project, Higher Education Institutions must make a specific diagnosis of their reality, deeply analyzing the internal and external variables of the institution and its students.
\end{abstract}

Keywords: Higher Education; Dropout; Performance; Determinant Factors.

\section{Resumen}

La evasión o abandono de la educación superior, es un tema que se ha estudiado de manera más significativa en los últimos años. Se enmarca no solo en la preocupación de las políticas afirmativas para la inclusión estudiantil, sino, en particular, de las instituciones privadas, considerando que tienen el mayor porcentaje de estudiantes en esta situación y, por lo tanto, los principales interesados en mantenerlos en sus cursos. Este artículo, entonces, tiene como objetivo general analizar las razones que llevan a los estudiantes a abandonar la Educación Superior presencial. La metodología utilizada para esta investigación se basa en procedimientos de análisis bibliográfico y documental. Para ello, se utiliza una colección digital, con la ayuda de Internet, para revisiones bibliográficas, artículos, monografías y disertaciones sobre este tema. El estudio indica que la falta de conocimiento sobre el curso elegido, las incertidumbres sobre las posibilidades de carrera en el área, las dificultades económicas de los estudiantes, el bajo rendimiento académico y la necesidad de articular tiempo para el estudio y el trabajo se encuentran entre las razones más citadas para la deserción en la Educación Superior. Por lo tanto, para trabajar en un proyecto de reducción del abandono, las Instituciones de Educación Superior deben realizar un diagnóstico específico de su realidad, analizando en profundidad las variables internas y externas de la institución y sus estudiantes.

Palabras clave: Educación Superior; Evasión; Rendimiento; Factores Determinantes. 


\section{Introdução}

A evasão ou abandono no âmbito da educação superior vem sendo estudada de forma mais significativa nos últimos anos, por causa da redução da demanda de alunos. Insere-se não só na preocupação das políticas afirmativas de inclusão do estudante, mas, em especial, das instituições privadas, tendo em vista serem as que possuem os maiores percentuais de estudantes nessa situação e, por conseguinte, as principais interessadas em mantê-los em seus cursos. No entanto, é um fenômeno educacional complexo, ocorre em todos os tipos de Instituição de Ensino Superior (IES) e afeta o sistema educacional como um todo, bem como o desenvolvimento humano.

Tem-se presenciado, no Brasil nos últimos anos, um crescimento significativo no Ensino Superior. Dados do censo da educação superior, publicado pelo Instituto Nacional de Estudos e Pesquisas Educacionais Anísio Teixeira (Inep, 2018), demonstram que, em 2017, as matrículas alcançaram 8.286.663, um crescimento notável de 107,5\% em relação a 2003. Do total das matrículas, $25 \%$ estão no setor público (1.961.002) e 75\% no privado (5.867.011).

No que tange à evasão, houve uma oscilação, nos últimos anos, em torno de 20-25\% ao ano. Levando-se em consideração um universo de cerca de 7 milhões de universitários, isso representa algo como 1,4 milhão de estudantes, um valor extremante elevado para um país que carece de profissionais qualificados. Assim como acontece com a ociosidade, a maior evasão concentra-se na rede privada de Ensino Superior que, no ano de 2013, viu 27,4\% de seus alunos evadirem, ao passo que, no mesmo ano, 17,8\% evadiram da rede pública (Inep, 2014).

Frente a esses números alarmantes, entender as causas da evasão do alunado deveria ser uma tarefa primordial de cada Instituição de Ensino Superior (IES). Mas o que vemos é que poucas instituições apuram o contingente de alunos que evadem, os cursos onde o fenômeno é mais preocupante e as causas que levam os alunos a abandonarem seus cursos. Acima de tudo, poucas IES buscam implementar políticas e estratégias que mitiguem a evasão. Em geral, costuma-se atribuir aos alunos a responsabilidade pelo abandono da universidade. Porém, isso não é verdade, já que fatores internos à instituição também têm sua parcela de contribuição na evasão.

Existe uma perda financeira para as IES e também para os alunos e familiares que, além dessa perda, também tem um custo social. A formação superior possibilita acessar patamares maiores de renda a curto, médio e longo prazo. Portanto, a evasão é um prejuízo para IES, para família, para o aluno e para o país.

A partir dessa contextualização inicial, o problema de pesquisa que se busca responder neste estudo é: Quais as causas que levam os alunos a evadirem do Ensino Superior presencial? Assim, esta pesquisa tem como objetivo geral analisar os motivos que levam os alunos ingressantes a evadirem do Ensino Superior presencial.

A fim de responder tal questão e atingir o objetivo aqui proposto, este trabalho está organizado em quatro seções além desta Introdução. A primeira é a Metodologia, na qual é apresentado o tipo de pesquisa realizada e os autores utilizados. Em Resultados e Discussão, há um breve histórico da Educação Superior no Brasil, estudos sobre a evasão no Ensino Superior e conceitos e causas dessa evasão, bem como sua gestão. Na terceira parte, Considerações Finais, é apresentado a retomada as causas da evasão dos acadêmicos do ensino e proposto o que pode ser feito pelas Instituições de Ensino Superior. Por fim, há a lista de Referências utilizadas para embasar esta pesquisa.

\section{Metodologia}

A metodologia é constituída pela estratégia de análise bibliográfica e documental, que implica em um conjunto ordenado de procedimentos de busca por soluções, atento ao objeto de estudo (Severino, 2007). Configura-se a partir de uma abordagem qualitativa, pois, de acordo com Lüdke e André (1986), apresenta algumas características, entre as quais podem ser salientadas: o ambiente natural (o mundo real) como fonte para a coleta de dados e a interação entre sujeito, pesquisador e 
objeto. Para esta pesquisa, foram utilizados acervo digital, com auxílio de internet para realizações revisões bibliográficas, artigos, monografias e dissertações. Com isso, criou-se a categoria de análise de dados intitulada "gestão da evasão", correspondendo a $26,82 \%$ das dissertações e teses e $29,03 \%$ dos artigos localizados. Nesses estudos citados, são abarcadas discussões diversas, tais como: identificação dos fatores anteriores ao ingresso que contribuem para a evasão (Brissac, 2009); opiniões e estratégias de coordenadores em relação ao fenômeno (Lima, 2012); e mecanismos de controle da evasão (Ney, 2010; Tontini; Walter, 2014).

\section{Resultados e Discussão}

\subsection{Histórico da Educação Superior no Brasil}

O cenário educacional tem presenciado um acirramento da competitividade entre as Instituições de Ensino Superior Privadas. Dados divulgados pelo Instituto Nacional de Estudos e Pesquisas Educacionais Anísio Teixeira - INEP (2009), por meio do Censo da Educação Superior de 2008, registram que o maior número de faculdades $(93,1 \%)$ e centros universitários (96\%) está vinculado ao setor privado, enquanto as universidades estão distribuídas, em proporção aproximada, entre o setor público (53\%) e privado (47\%). O Ensino Superior passou por um período de reestruturação e expansão, no qual foram criadas novas faculdades e políticas públicas que buscavam auxiliar o acesso e a permanência no Ensino Superior. Esse cenário está ligado ao apelo pelo desenvolvimento do país, através do aumento do número de mão de obra qualificada com um curso de graduação, e pelo mercado de trabalho, que continua competitivo e, atualmente, mais exigente quanto à qualidade dos profissionais, os quais terão acesso às melhores vagas.

Ao estudar cada um dos triênios durante a expansão do Ensino Superior no Brasil, percebe-se que teve uma preponderância de contribuição, ora da iniciativa pública ora das IES privadas. Tachibana, Filho e Komatsu (2015) citam que o período de maior expansão de ingresso, através de processo seletivo, na graduação presencial, ocorreu entre 1996 e 2008, uma vez que o acesso ao Ensino Superior praticamente triplicou, saindo de 514 mil para 1,506 milhão de ingressantes. Nesse processo, em específico, foi mais importante a participação do setor privado, visto que esse cresceu $245 \%$, ao passo que o setor público cresceu $85 \%$.

\subsection{Estudos sobre evasão na Educação Superior}

Com o panorama de expansão da educação superior em curso, os estudos relacionados à evasão dos acadêmicos ganharam corpo, em compasso com o aumento do número de estudantes matriculados nos cursos de graduação das IES brasileiras, embora ainda considerados escassos na literatura (Santos Junior; Real, 2017). No Brasil, as preocupações com este fenômeno iniciaram-se de modo efetivo em 1995, entrando para a agenda governamental a partir do "Seminário sobre evasão nas universidades brasileiras", organizado pela Sesu/MEC, em fevereiro de 1995 (Kipnis, 2000). No seminário, foi instituída a "Comissão Especial de Estudos sobre a Evasão nas Universidades Públicas Brasileiras", configurando-se como um dos primeiros esforços para identificar as causas do fenômeno da evasão no país e sugerir medidas para minimizar os índices observados nas instituições de educação superior públicas, partindo de uma uniformização do processo de coleta e tratamento de dados.

Em outros países, esta temática já vem sendo debatida há algumas décadas, pois desde meados de 1960 modelos teóricos vêm sendo desenvolvidos com o intuito de se entender melhor o fenômeno da evasão, conforme destaca Freitas (2009). No contexto sul-americano, verifica-se a presença de estudos recentes, visando, sobretudo, à identificação de índices de evasão e à adoção de estratégias de controle. Tendo como base o ano de 2000, Parrino (2009) reuniu os dados referentes ao ingresso à educação dos jovens entre 18 e 29 anos e as taxas de evasão em cinco países sul-americanos: Argentina, Chile, 
Brasil, Uruguai e Paraguai. Logo, constatou que o Brasil possuía o menor índice de evasão (14\%) no ano considerado na pesquisa (Santos Junior; Real, 2017).

Há uma complexidade intrínseca em relação ao fenômeno da evasão, uma vez que, embora se perceba certa variedade de tratamentos dados ao processo, ainda há muito que se discutir. Para isso, é preciso considerar a dinâmica de crescimento da educação superior no Brasil e os meandros que a envolvem, os quais têm possibilitado ampliações nas vertentes de pesquisa (Santos Junior; Real, 2017). Para Baggi e Lopes (2011), que realizaram revisão de literatura acerca do tema, esta complexidade envolve questões pedagógicas, psicológicas, sociais, políticas, econômicas, administrativas, dentre outras. Entretanto, tal complexidade pode ser observada desde questões conceituais, em que se verifica um emaranhado de definições para o fenômeno da evasão, à multiplicidade de metodologias para identificação de seus índices (Pereira Junior, 2012 apud Santos Junior; Real, 2017).). Em relação ao conceito, para Baggi e Lopes (2011, p. 370), trata-se da "saída do aluno da instituição antes da conclusão do seu curso". Abbad, Carvalho e Zerbini (2006, p. 02) definem evasão como a "desistência definitiva do aluno em qualquer etapa do curso".

Os pesquisadores vêm apontando os motivos que levam ao fenômeno da evasão, sendo amplamente utilizado o diagnóstico, a entrevista ou a aplicação de questionário aos evadidos para entender tais causas. Por outro lado, Tinto (1975) propôs o entendimento do processo de evasão a partir de percurso longitudinal, em que os principais fatores relacionados a este fenômeno seriam aqueles que envolvem a integração entre o indivíduo e os sistemas acadêmico e social. Para o autor, os estudantes menos envolvidos com a instituição possuem maiores chances de abandonar o curso iniciado, tendo em vista que, comumente, não se integram com demais alunos de mesma turma e/ou da instituição como um todo (Santos Junior; Real, 2017).

Ao partir das concepções de Tinto, Pereira Junior (2012) buscou identificar a relação entre o processo de evasão aos compromissos do estudante relacionados à sua graduação, ao curso e à instituição, concluindo que há necessidade de maior preocupação e acompanhamento dos estudantes ingressantes pelas instituições em aspectos relacionados ao curso e à carreira profissional. Nesta direção, o trabalho de Pereira Junior (2012) faz parte de um percentual expressivo de trabalhos encontrados, realizados tanto em instituições públicas quanto privadas, que discutem a evasão com um viés mais direcionado ao fator institucional e que apresentam medidas de combate à evasão. Tais trabalhos foram incluídos na categoria "gestão da evasão", correspondendo a $26,82 \%$ das dissertações e teses e $29,03 \%$ dos artigos localizados. Nestes estudos citados, são abarcadas discussões diversas, tais como: identificação dos fatores anteriores ao ingresso que contribuem para a evasão (Brissac, 2009); opiniões e estratégias de coordenadores em relação ao fenômeno (Lima, 2012); e mecanismos de controle da evasão (Ney, 2010; Tontini; Walter, 2014). Essas discussões assumem relevância no atual contexto, visto que a ampliação das políticas de expansão do acesso e da permanência na educação superior pressupõe o acompanhamento sistemático dos sujeitos que ingressam no sistema, com o intuito de otimizar a implementação efetiva de tais políticas. Nesse caso, a atuação institucional adquire importância estratégica para o controle da evasão, fazendo-se necessário aos gestores conhecer as expectativas educacionais dos indivíduos que acessam à educação superior, a fim de ampliar o entendimento do fenômeno (Tinto, 1975) (Santos Junior; Real, 2017).

\subsection{Conceitos e Causas de evasão no Ensino Superior}

No que diz respeito ao seu conceito ou definição, a evasão também apresenta diferentes significados presentes na literatura brasileira. Gaioso (2005) a define como sendo a interrupção no ciclo de estudos, em qualquer nível de ensino. Kira (2002), tendo como cenário específico a educação superior, afirma que o termo evasão é frequentemente utilizado para se referir à "perda" ou "fuga" de alunos da universidade. Outros autores, como é o caso de Baggi e Lopes (2011), definem a evasão como a saída do aluno da instituição antes da conclusão de seu curso. 
O estudante universitário pode desligar-se de três maneiras (Lobo, 2012; Machado, 2005; Polydoro, 2000):

a) evasão de curso: quando o estudante se desliga de alguma maneira do curso que frequenta para ingressar em outro curso, seja na mesma IES ou em outra;

b) evasão da instituição: o estudante deixa a IES para ingressar em outra, seja no mesmo curso ou em outro;

c) evasão do sistema: o estudante se desliga do curso da IES, no qual está matriculado, e não ingressa em outro curso na mesma IES ou em outra, tampouco no mesmo curso em outra IES, deixando o sistema de educação superior, sem perspectivas de retorno.

Das três instâncias de evasão elencadas, a que traz maior efeito negativo para a educação superior, para a sociedade como um todo e para o indivíduo é a evasão do sistema. Essa, segundo Lobo (2012, p. 39), “[...] é exatamente aquela que exige políticas públicas, que vão além das questões institucionais, acadêmicas ou até das individuais, uma vez que a evasão é um dos mais sérios problemas de um sistema educacional de qualquer nível". Consequentemente, esse tipo de evasão traz reflexos para o indivíduo, para a sociedade e até mesmo ao desenvolvimento de uma nação, que não poderá contar com cidadãos que poderiam contribuir, de maneira eficaz, para seu desenvolvimento social e tecnológico.

No artigo "Evasão no Ensino Superior: Um Estudo Sistemático", Rita Petrarca Teixeira, Manuir José Mentges e Adriana Justin Cerveira Kampff (2019) fazem um estudo sistemático de 34 trabalhos que apresentavam, como resultados de suas investigações, um ou mais motivos para evasão. Neste estudo, denominado estado da arte, Teixeira et al (2019) analisa a produção bibliográfica que aborda evasão no Ensino Superior, por meio de pesquisas ou artigos publicados em três bases de dados, a saber, na Biblioteca Digital Brasileira de Teses e Dissertações (BDTD, 2018), na Revista de Gestão Universitária da América Latina (GUAL, 2018) e nos Anais da Conferência Latino-americana de Abandono na Educação Superior (CLABES, 2018) entre de 2013 e agosto de 2018, a partir dos termos "evasão", "permanência" e "ensino superior".

Na Biblioteca Digital Brasileira de Teses e Dissertações (BDTD, 2018), foram localizados pelos autores 29 trabalhos, sendo 27 dissertações de mestrado e 2 teses de doutorado. Na Revista de Gestão Universitária da América Latina (GUAL, 2018), após a exclusão dos artigos que tratavam de ensino à distância ou se referiam a cursos tecnólogos, foram encontrados seis artigos. Já nos Anais da Conferência Latino-americana de Abandono na Educação Superior (CLABES, 2018), foram selecionados 10 artigos que correspondiam aos critérios do estudo.

Onze, dos 45 trabalhos analisados pelos autores, não detalhavam claramente motivos de evasão, destacando apenas a multiplicidade de fatores que podem levar ao abandono. Em três destes trabalhos, há uma reflexão sobre os altos índices de evasão em IES públicas e, neste contexto, a afirmação do prejuízo financeiro e social da não conclusão do Ensino Superior pelos sujeitos. De forma complementar, 34 trabalhos apresentavam, como resultados de suas investigações, um ou mais motivos para evasão. O Quadro 1 apresenta os motivos de evasão citados nesses trabalhos. Para cada um dos motivos, destacase a recorrência - quantidade de trabalhos em que ele aparece citado -, quantos desses trabalhos eram de IES públicas, quantos eram de IES privadas e quantos eram do tipo "misto", ou seja, baseados em agrupamentos de instituições de categorias administrativas diferentes. Como é possível observar no Quadro 1, o pouco conhecimento sobre o curso escolhido e as incertezas em relação às possibilidades de carreira na área, as dificuldades financeiras dos estudantes, o baixo desempenho acadêmico e a necessidade de articular tempo para estudo e trabalho estão entre os motivos mais citados para o abandono no Ensino Superior. 
Quadro 1 - Motivos de Evasão

\begin{tabular}{|c|c|c|c|c|}
\hline Motivo de Evasão & Recorrência & $\begin{array}{l}\text { IES } \\
\text { Públicas }\end{array}$ & $\begin{array}{l}\text { IES } \\
\text { Privadas }\end{array}$ & Misto \\
\hline Questões de cunho vocacional / opção por novos cursos & 16 & 12 & 2 & 2 \\
\hline $\begin{array}{l}\text { Condições socioeconômicas enfrentadas pelos alunos } \\
\text { (dificuldades financeiras) }\end{array}$ & 15 & 5 & 8 & 2 \\
\hline Problemas de baixo desempenho e reprovações nas disciplinas & 9 & 7 & 2 & 0 \\
\hline $\begin{array}{l}\text { Dificuldade de compatibilização do curso com a necessidade } \\
\text { de trabalhar }\end{array}$ & 8 & 4 & 4 & 0 \\
\hline Fatores didático-pedagógicos / metodológicos dos professores & 8 & 4 & 2 & 2 \\
\hline $\begin{array}{l}\text { Pouca perspectiva de carreira / incertezas quanto ao mercado } \\
\text { de trabalho }\end{array}$ & 7 & 6 & 1 & 0 \\
\hline Lacunas de aprendizagem da Educação Básica & 5 & 2 & 2 & 1 \\
\hline Problemas de infraestrutura e serviços institucionais & 3 & 0 & 3 & 0 \\
\hline Residir distante da IES & 3 & 1 & 2 & 0 \\
\hline $\begin{array}{l}\text { Insatisfação com o curso (currículo fragmentado, pouca } \\
\text { visibilidade sobre a prática) }\end{array}$ & 3 & 3 & 0 & 0 \\
\hline $\begin{array}{l}\text { Baixo nivel de relacionamento entre os sujeitos (professores e } \\
\text { estudantes) }\end{array}$ & 3 & 2 & 1 & 0 \\
\hline Troca de IES & 2 & 0 & 2 & 0 \\
\hline Problemas de relacionamento com a coordenação & 2 & 1 & 1 & 0 \\
\hline $\begin{array}{l}\text { Dificuldade de acesso ao Programa de Assistência Estudantil } \\
\text { (valor financeiro adicional para alunos de IES públicas) }\end{array}$ & 1 & 1 & 0 & 0 \\
\hline Segurança pública & 1 & 0 & 1 & 0 \\
\hline Gravidez & 1 & 0 & 1 & 0 \\
\hline
\end{tabular}

Fonte: Teixeira et al. (2019).

Para o MEC (1996), há três fatores que influenciam a evasão no Ensino Superior. Os fatores característicos individuais do estudante referente à evasão estão relacionados às habilidades de estudo, à personalidade, à formação escolar anterior, à escolha precoce da profissão, às dificuldades pessoais de adaptação à vida universitária, ao desencanto com o curso escolhido, às dificuldades recorrentes de reprovações ou baixa frequência e à desinformação a respeito da natureza dos cursos (MEC, 1996). Já os fatores internos às instituições, referentes à evasão, podem se caracterizar por questões peculiares a própria academia, à falta de clareza sobre o projeto pedagógico do curso, ao baixo nível de didática-pedagógica, à cultura institucional de desvalorização da docência e à estrutura insuficiente de apoio ao ensino (MEC, 1996). Por fim, os fatores externos às instituições são o mercado de trabalho, o reconhecimento social na carreira escolhida, a conjuntura econômica, a desvalorização da profissão, a dificuldade de atualizar-se perante as evoluções tecnológicas, econômicas e sociais da contemporaneidade e as políticas governamentais (MEC, 1996).

Em outro estudo, elaborado por Morosini (et al., n/d), intitulado "A evasão na educação superior no Brasil: uma análise da produção de conhecimento nos periódicos Qualis entre 2000-2011”, foram identificados oito principais motivos, presentes nos trabalhos dos pesquisadores brasileiros, que levam aos ingressos evadirem do ensino superior, sendo eles:

1. Aspectos financeiros relacionados à vida pessoal ou familiar do estudante;

2. Aspectos relacionados à escolha do curso, expectativas pregressas ao ingresso, nível de satisfação com o curso e com a universidade;

3. Aspectos interpessoais - dificuldades de relacionamento com colegas e docentes;

4. Aspectos relacionados com o desempenho nas disciplinas e tarefas acadêmicas - índices de aprovação, reprovação e repetência; 
5. Aspectos sociais, como baixo prestígio social do curso, da profissão e da universidade elegida;

6. Incompatibilidade entre os horários de estudos e as demais atividades, como, por exemplo, o trabalho;

7. Aspectos familiares como, por exemplo, responsabilidade com filhos e dependentes, apoio familiar quanto aos estudos etc.;

8. Baixo nível de motivação e compromisso com o curso (Morosini et al., n/d, p. 8).

\section{Considerações Finais}

Esta pesquisa procurou estudar e identificar quais as causas e razões que levaram os alunos a evadirem do Ensino Superior presencial. Através das leituras e estudos efetuados nas literaturas, se identificam várias causas que ocasionam a evasão, sendo os principais: problemas financeiros, dificuldade em conciliar os estudos com o trabalho, escolha do curso, repetência em disciplinas, falta de integração a IES.

O Ensino Superior Privado convive com limitações de recursos, devido à redução da demanda somada a concorrência de grandes grupos econômicos. Isso porque, no setor educacional, a partir de 2007, a abertura de capital na Bolsa de Valores com participação de fundos de investimento internacionais trouxe uma lógica capitalista de mercado de educação, no qual o objetivo principal é o lucro, com ganho de escala através da incorporação de Faculdades e Universidades. Essas não suportam esta concorrência, bem como investimento de grandes volumes de recursos em marketing, com grandes redes de ensino presencial e Educação a Distância $(\mathrm{EaD})$.

Temos neste cenário, também, o avanço dos cursos $\mathrm{EaD}$ em outros cursos tradicionalmente presenciais, como Educação Física, que tem como um dos componentes da evasão, nos últimos anos, a transferência de vagas para o $\mathrm{EaD}$, frente ao baixo valor de mensalidades oferecido pelas grandes redes educacionais. Recentemente, foi aprovado pelo MEC a abertura de cursos de Direito em EaD, que também terá, a curto prazo, a redução de demanda nos cursos presenciais como mais um componente dos seus índices de evasão. Parte do aumento da evasão se deve à redução das políticas públicas de apoio do FIES e ProUni à população mais carente, que tem dificuldade em acessar às vagas no Ensino Superior Público.

Conforme as análises e estudos apresentados neste artigo, a evasão se compõem de vários motivos e causas, que podem variar de região para região. Em cada IES, estas causas e motivos podem ter intensidade diferentes. Portanto, para se trabalhar um projeto de redução da evasão, as IES deverão fazer um diagnóstico específico de sua realidade, analisando profundamente as varáveis internas e externas da instituição e de seus alunos. Dessa forma, poderão identificar os principais motivos da evasão dos acadêmicos e traçar medidas para reduzir e até mesmo eliminar tal ocorrência.

Este artigo não tem a pretensão de esgotar o tema sobre evasão, mas de contribuir com as pesquisas já existentes e servir de fonte de estudo para novas pesquisas nesta área, de fundamental importância para a manutenção, desenvolvimento e crescimento do Ensino Superior Privado. A partir disso, espera-se contribuir para a reflexão e desenvolvimento de novos trabalhos sobre o tema. Através dos quais poder-se-ão pensar em IES específicas, buscando diagnosticar os motivos das evasões e sugerir medidas para minimizar os índices observados nas instituições de educação superior públicas e/ou privadas.

\section{Referências}

Abbada, Gardênia; Carvalho, Renata Silveira; Zerbini, Thaís. (2006). Evasão em curso via internet: explorando variáveis explicativas. RAE- eletrônica, São Paulo, 5(2), 01-26.

Baggi, Cristiane Aparecida dos Santos; Lopes, Doraci Alves. (2011). Evasão e avaliação institucional no ensino superior: uma discussão bibliográfica. Avaliação, 16(2), 355-374.

Brissac, Rafaela de Menezes Souza. (2009). Fatores anteriores ao ingresso como preditivos de evasão nos anos iniciais dos cursos superiores de tecnologia (Dissertação de Mestrado). Universidade Estadual de Campinas, Campinas, SP, Brasil.

Freitas, Katia Siqueira. (2009). Alguns estudos sobre evasão e persistência de estudantes. Eccos-Revista Científica, 2(1), 247-264. 
Gaioso, Natália Pacheco de Lacerda. (2005). A evasão discente na educação superior no Brasil: na perspectiva de alunos e dirigentes (Dissertação de Mestrado). Universidade Católica de Brasília, Brasília- DF, Brasil.

Instituto Nacional de Estudos e Pesquisas Educacionais Anísio Teixeira (INEP). (2009). Resumo técnico: censo da educação superior 2008. Brasília,; Autor.

Instituto Nacional de Estudos e Pesquisas Educacionais Anísio Teixeira (INEP). (2014). Censo da Educação Superior 2013. Brasília: Autor. Recuperado de http://download.inep.gov.br/educacao_superior/censo_superior/apresentacao/2014/coletiva_censo_superior_2013.pdf

Instituto Nacional de Estudos e Pesquisas Educacionais Anísio Teixeira (INEP). (2015). Censo da Educação Superior 2014. Brasília: Autor. Recuperado de http://download.inep.gov.br/educacao_superior/censo_superior/apresentacao/2015/apresentacao_ministro.pdf

Instituto Nacional de Estudos e Pesquisas Educacionais Anísio Teixeira (INEP). (2018). Sinopse Estatística da Educação Superior 2017. Brasília: Autor. Recuperado de http://portal.inep.gov.br/basica-censo-escolar-sinopse-sinopse

Kipnis, Bernardo. (2000). A pesquisa institucional e a educação superior brasileira: um estudo de caso longitudinal da evasão. Linhas Críticas, 6(1), 109-130.

Kira, Luci Frare. (2002). A evasão no ensino superior: o caso do curso de pedagogia da Universidade Estadual de Maringá (1992 - 1996) (Dissertação de Mestrado). Universidade Metodista de Piracicaba, Piracicaba, São Paulo, Brasil.

Lima, Edileusa Esteves. E. (2012). A expansão das licenciaturas na UFMG: estratégias de gestão de evasões de alunos face às metas do Reuni (Dissertação de Mestrado). Centro Universitário UNA, Belo Horizonte, Brasil.

Lobo, Maria Beatriz de Carvalho Melo. (2012). Panorama da Evasão no Ensino Superior Brasileiro: Aspectos Gerais das Causas e Soluções. Cadernos ABMES, 25, 09-58.

Lüdke, M.; André, M. E. D. A. (1986). Pesquisa em educação: abordagens qualitativas. EPU.

Machado, Osmar Aparecido. (2005). Evasão de alunos de cursos superiores: fatores motivacionais e de contexto (Dissertação de Mestrado). Universidade Estadual de Londrina.

MEC. (1996). Diplomação, retenção e evasão nos cursos de graduação em instituições de ensino superior públicas. Revista de rede de avaliação institucional da educação superior. 1(2), 55-65.

Morosini, Marília Costa; Casartelli, Alam de Oliveira; Silva, Ana Cristina Benso; Santos, Betina Steren; Schmitt, Rafael Eduardo; Gessinger, Rossana Maria. (n/d). A evasão na educação superior no Brasil: uma análise da produção de conhecimento nos periódicos Qualis entre $2000-2011$. Recuperado de http://www.alfaguia.org/

Ney, Otávio Abrantes de Sá. (2010). Sistemas de informação acadêmica para o controle da evasão (Dissertação de Mestrado). Universidade Federal da Paraíba, João Pessoa, Brasil.

Parrino, María Del Carmem. (2009). La deserción y la retención de alunos: um viejo conflito que requiere pensar nuevas soluciones. GUAL, 2(1), 01-15.

Pereira Junior, Edgar. (2012). Compromisso com o graduar-se, com a instituição e com o curso: estrutura fatorial e relação com a evasão (Dissertação de Mestrado). Universidade Estadual de Campinas, Campinas, Brasil.

Polyodoro, Soely Aparecida Jorge. (2000). O trancamento de matrícula na trajetória acadêmica do universitário: condições de saída e de retorno à instituição (Tese de Doutorado). Universidade de Campinas.

Santos Junior, José da Silva; Real, Giselle Cristina Martins. (2017). A evasão na educação superior: o estado da arte das pesquisas no Brasil a partir de 1990. Avaliação, Campinas; Sorocaba, SP, v. 22, n. 2, p.385-402.

Severino, Antônio Joaquim. (2007). Metodologia do trabalho científico. CORTEZ.

Silva, Maria das Graças Martins; Veloso, Tereza Christina Mertens Aguiar. (2013). Acesso nas políticas de educação superior: dimensões e indicadores em questão. Avaliação, 18(3), 727-747.

Silva Filho, Roberto Leal Lobo et al. (2007). A evasão no Ensino Superior brasileiro. Cadernos de Pesquisa, 37(132), 641-659.

Tachibana, Thiago Yudi; Filho, Naercio Menezes; Komatsu, Bruno. (2015). Ensino superior no Brasil. Policy Paper Insper, 14, 1-53. Recuperado de https://www.insper.edu.br/wp-content/uploads/2012/05/Ensino-superior-no-Brasil.pdf

Teixeira, Rita Petrarca et al. (2019). Evasão No Ensino Superior: Um Estudo Sistemático. PUCRS.

Tinto, Vincent. (1975). Dropout from higher education: a theoretical synthesis of recent research. Review of Educational Research, 45(1), 89-125.

Tontini, Gérson; Walter, Silvana Anita. (2014). Pode-se identificar a propensão e reduzir a evasão de alunos?: ações estratégicas e resultados táticos para instituições de ensino superior. Avaliação, 19(1), 89-110. 